\title{
Quantitative proteomics of Lactococcus lactis F44 under cross-stress of low pH and lactate
}

\author{
Hao $\mathrm{Wu},{ }^{,} \dagger^{1}$ Yue Zhao, ${ }^{*}{ }^{1}$ Yuhui Du, ${ }^{*}$ Sen Miao, ${ }^{*} \dagger$ Jingui Liu, ${ }^{*} \dagger$ Yanni Li, ${ }^{*}$ Qinggele Caiyin, ${ }^{*}$ \\ and Jianjun Qiao* $† \ddagger^{2}$ \\ *Department of Pharmaceutical Engineering, School of Chemical Engineering and Technology, and \\ †Key Laboratory of Systems Bioengineering (Ministry of Education), Tianjin University, Tianjin 300072, P. R. China \\ †SynBio Research Platform, Collaborative Innovation Center of Chemical Science and Engineering (Tianjin), Tianjin 300072, P. R. China
}

\begin{abstract}
Lactococcus lactis encounters 3 environmental stimuli, $\mathrm{H}^{+}$, lactate, and undissociated lactic acid, because of the accumulation of lactic acid - the predominant fermentation product. Few studies have examined how these stimuli synergistically affect the bacteria. Herein, we analyzed the dissociation degree of lactic acid at different $\mathrm{pH}$ and investigated the cellular response to cross-stress in L. lactis ssp. lactis F44 through quantitative proteomic analysis using isobaric tags for relative and absolute quantitation of 3 groups: $0 \%$ lactic acid with $\mathrm{pH} 4.0$ and $0 \%$ lactic acid with $\mathrm{pH} 5.0$ for acid stress; $2 \%$ lactic acid with $\mathrm{pH} 7.0$ and $3 \%$ lactic acid with $\mathrm{pH} 7.0$ for lactate stress; and $2 \%$ lactic acid with $\mathrm{pH} 4.0,2 \%$ lactic acid with $\mathrm{pH} 5.0,3 \%$ lactic acid with $\mathrm{pH} 4.0$, and $3 \%$ lactic acid with $\mathrm{pH} 5.0$ for cross-stress. We observed that the metabolisms of carbohydrate and energy were inhibited, which might be due to the feedback inhibition of lactic acid. The arginine deiminase pathway was improved to maintain the stability of intracellular $\mathrm{pH}$. Additionally, some differentially expressed genes associated with the general stress response, amino acid metabolism, cell wall synthesis, and regulatory systems played significant roles in stress response. Overall, we highlighted the response mechanisms to lactic acid stress and provided a new opportunity for constructing robust industrial strains.
\end{abstract}

Key words: Lactococcus lactis, stress response, quantitative proteomics

\section{INTRODUCTION}

Lactococcus lactis is a gram-positive bacterium that has great economic value because of its characteristics

Received February 15, 2018.

Accepted April 13, 2018.

${ }^{1}$ These authors contributed equally to this work.

${ }^{2}$ Corresponding author: jianjunq@tju.edu.cn of simple metabolism, rapid growth, lack of toxic substances, and extensive usefulness in the food industry (Song et al., 2017). During fermentation, L. lactis is exposed to several environmental stimuli, especially lactic acid, that results in the inhibition of cell growth and the accumulation of important products, such as nisin (Shimizu et al., 1999; Guerra and Pastrana, 2003).

Lactic acid is a weak organic acid with a $\mathrm{p} K_{\mathrm{a}}$ of 3.86 (Eyal and Canari, 1995). The lipophilic undissociated lactic acid can diffuse across the cell membrane freely; once inside the cell, this lactic acid dissociates and releases protons to acidify the cytoplasm (Rosengren et al., 2013). Therefore, $\mathrm{H}^{+}$, lactate, and undissociated lactic acid should be taken into account when assessing the detrimental effects of lactic acid. Lactic acid restrains cell growth by causing loss of membrane potential (Axe and Bailey, 1995), acidification of cytoplasm induced by dissociated protons (Shelef, 1994), and indirect suppression of $\mathrm{NAD}^{+}$regeneration via intracellular accumulation of anions (Russell, 1992; Russell and Diez-Gonzalez, 1998). In addition, a large number of acid-resistance mechanisms have been discussed, such as $\mathrm{F}_{1} \mathrm{~F}_{0}$-ATPase, glutamate decarboxylase system, arginine deiminase pathway (Marquis et al., 1987; Gruening et al., 2006; Lucas et al., 2007; Vrancken et al., 2009), abundance of chaperones or DNA repair system (Hanna et al., 2001; Frees et al., 2003; Desmond et al., 2004), alterations in the composition of the cell envelope (Montanari et al., 2010), and transcriptional regulation (Zhai et al., 2014).

The effects of low-pH stress on proteome and transcriptome levels have been determined in multiple lactic acid bacteria (LAB), such as L. lactis (Frees et al., 2003; Budin-Verneuil et al., 2005), Lactobacillus casei (Broadbent et al., 2010), Lactobacillus reuteri (Wall et al., 2007; Lee et al., 2008), Lactobacillus rhamnosus (Koponen et al., 2012), Streptococcus thermophilus (Arena et al., 2006), and Bifidobacterium longum (Sánchez et al., 2007). High-throughput sequencing technology aids in systematic analysis of organisms under environmental stresses. Xie et al. (2004) performed an oligonucleotide 
microarray to profile gene expression levels under acid, osmotic, and heat stress in L. lactis ssp. lactis IL1403; simultaneously, the authors explained the differences of response mechanisms under acid stress between $L$. lactis strains MG1363 and IL1403. Pieterse et al. (2005) studied the transcriptome of Lactobacillus plantarum in diverse concentrations of lactic acid, osmolality, and $\mathrm{pH}$ value, and many responsive mechanisms under lactic acid stress were identified. Desmond et al. (2004) revealed that the expression of GroEL in Lactobacillus paracasei NFBC338 was increased under heat adaptation conditions, and the groESL-overexpressing strains exhibited a higher tolerance to heat and butanol. Sánchez et al. (2007) compared the protein maps of B. longum biotype longum NCIMB 8809 and its acidresistant mutant, and results indicated that the AA deamination pathway could neutralize internal protons through the production of ammonium. Similarly, a comparative proteomic study of $L$. casei Zhang and its acid-resistant mutant showed that several key proteins associated with cellular metabolism, translation, DNA replication, and chaperones were induced to protect the cells of the mutant (Wu et al., 2012). Zhai et al. (2014) used the proteome complemented by the transcriptome to uncover the cellular response in Lactobacillus delbrueckii during acid adaptation and identified Ldb0677, a novel transcriptional regulator related to acid stress. Moreover, that group also found pyruvate kinase (Pyk) could increase acid resistance probably by enhancing the fatty acid biosynthesis, and they disclosed that it was regulated by the transcriptional regulator CcpA via bacterial one-hybrid technology (Zhai et al., 2015).

Although many studies have investigated the molecular basis of acid stress in LAB, response mechanisms under lactic acid stress are still poorly understood. In this study, we applied the isobaric tags for relative and absolute quantitation (iTRAQ) quantitative proteomics approach to determine the metabolic response of L. lactis ssp. lactis $\mathrm{F} 44$ under cross-stress of $\mathrm{H}^{+}$and lactate. This study will contribute to the construction of robust industrial strains.

\section{MATERIALS AND METHODS}

\section{Strains and Growth Conditions}

Lactococcus lactis ssp. lactis F44 was obtained by the genome shuffling of L. lactis ssp. lactis YF11 (accession number CGMCC7.52) in our previous study (Zhang et al., 2016). The inoculum was prepared at $30^{\circ} \mathrm{C}$ for 8 $\mathrm{h}$ (optical density at $600 \mathrm{~nm} \sim 1.5$ ) in seed medium and was inoculated (10\%) into the fresh fermentation medium with different 12 stress conditions: $1 \%$ lactic acid with $\mathrm{pH} 4.0, \mathrm{pH} 5.0, \mathrm{pH} 6.0$, or $\mathrm{pH} 7.0 ; 2 \%$ lactic acid with $\mathrm{pH} 4.0, \mathrm{pH} 5.0, \mathrm{pH} 6.0$, or $\mathrm{pH} 7.0$; or $3 \%$ lactic acid with $\mathrm{pH} 4.0, \mathrm{pH} 5.0, \mathrm{pH} 6.0$, or $\mathrm{pH} 7.0$. Samples were taken at $0.5,1,1.5$, and $2 \mathrm{~h}$. After collection by centrifugation $\left(8,228 \times g, 5 \mathrm{~min}, 4^{\circ} \mathrm{C}\right)$, the cell suspension was serially diluted with $0.9 \%$ normal saline. A total of $100 \mu \mathrm{L}$ of diluted samples was spread on seed medium agar plates in triplicate and incubated at $30^{\circ} \mathrm{C}$ for $48 \mathrm{~h}$. Cell survival numbers were estimated by calculating the average number of colony-forming units per milliliter through the plates with colonies. The seed medium and fermentation medium followed the composition in our previous study (Liu et al., 2017). The mediums were adjusted to the particular $\mathrm{pH}$ values with $18 \%$ hydrochloric acid or $10 \mathrm{~mol} / \mathrm{L}$ of sodium hydroxide. The growth characteristics were confirmed from 3 independent growth experiments. In the proteomic analysis, 8 conditions were carried out as follows: $\mathrm{pH} 5.0$ without lactic acid (L0P5) and $\mathrm{pH} 4.0$ without lactic acid (L0P4) for acid stress; $2 \%$ lactic acid with $\mathrm{pH} 7.0$ (L2P7) and $3 \%$ lactic acid with $\mathrm{pH}$ 7.0 (L3P7) for lactate stress; and 2\% lactic acid with pH 5.0 (L2P5), $2 \%$ lactic acid with $\mathrm{pH} 4.0$ (L2P4), $3 \%$ lactic acid with pH 5.0 (L3P5), and 3\% lactic acid with pH 4.0 (L3P4) for cross-stress. Cells for proteomic analysis were collected after $1 \mathrm{~h}$ of stress by centrifugation $\left(8,228 \times g, 5 \mathrm{~min}, 4^{\circ} \mathrm{C}\right)$.

\section{iTRAQ Quantitative Proteomics}

Protein preparation and digestion and iTRAQ labeling were conducted as in our previous study (Qiao et al., 2012). In brief, fermentation samples were frozen in liquid nitrogen after centrifugation $(8,228 \times g, 5$ min, $\left.4^{\circ} \mathrm{C}\right)$. Protein extraction, concentration measurement, SDS-PAGE, and protein digestion were then performed. Total proteins were digested by Trypsin Gold (Promega, Madison, WI) at $37^{\circ} \mathrm{C}$ for $16 \mathrm{~h}$, and the iTRAQ labeling of peptide samples was carried out using an iTRAQ Reagent 8-plex Kit (Applied Biosystems, Foster City, CA). Eight samples were individually iTRAQ labeled as follows: sample L3P4 (113 tag), sample L2P4 (114 tag), sample L3P7 (115 tag), sample L2P7 (116 tag), sample L2P5 (117 tag), sample L3P5 (118 tag), sample L0P5 (119 tag), and sample L0P4 (121 tag). The labeled peptides were then incubated at room temperature for $2 \mathrm{~h}$ and vacuum dried.

An LC-20AB HPLC Pump system (Shimadzu, Kyoto, Japan) was used to carry out strong cation exchange chromatography. The mixed peptides were resuspended in $4 \mathrm{~mL}$ of buffer $\mathrm{A}\left(25 \mathrm{mM} \mathrm{NaH} \mathrm{PO}_{4}\right.$ in $25 \%$ acetonitrile, $\mathrm{pH} 2.7$ ) and added to an Ultremex SCX column $(4.6 \times 250 \mathrm{~mm})$ containing $5-\mu \mathrm{m}$ particles 
(Phenomenex, Torrance, CA). The peptides were eluted at a $1-\mathrm{mL} / \mathrm{min}$ flow rate as follows: a gradient of buffer A for $10 \mathrm{~min}, 5$ to $60 \%$ buffer $\mathrm{B}\left(25 \mathrm{mM} \mathrm{NaH}_{2} \mathrm{PO}_{4}, 1\right.$ $M \mathrm{KCl}$ in $25 \%$ acetonitrile, $\mathrm{pH} 2.7$ ) for $27 \mathrm{~min}$, and 60 to $100 \%$ buffer B for $1 \mathrm{~min}$. Before the next sample injection, the system was performed with $100 \%$ buffer B for 1 min followed by buffer A for $10 \mathrm{~min}$, and the elution was monitored at $214 \mathrm{~nm}$. Fractions were then collected every $1 \mathrm{~min}$, desalted with a Strata X C18 column (Phenomenex), and vacuum dried.

\section{Liquid Chromatography-Electrospray lonization- Tandem MS Proteomic Analysis}

Samples were resuspended with buffer A (5\% acetonitrile, $0.1 \%$ formic acid) to a final concentration of 0.5 $\mu \mathrm{g} / \mu \mathrm{L}$ and centrifuged for the removal of insoluble substances $\left(20,000 \times g, 10 \mathrm{~min}, 4^{\circ} \mathrm{C}\right)$. Mass spectroscopy analysis was performed with the AB SCIEX TripleTOF 5600 mass spectrometer (AB Sciex, Concord, ON, Canada) coupled with an LC-20AD HPLC system (Shimadzu). The peptides were separated using a $2-\mathrm{cm}$ C18 trap column (inner diameter $=200 \mu \mathrm{m}$, Waters, Milford, MA) and a 10-cm analysis column (inner diameter $=75 \mu \mathrm{m}, 5 \mu \mathrm{m}$ of resin, $300 \AA$, Waters) by using the following method: the sample was loaded to the trap column at a constant flow rate of $8 \mu \mathrm{L} / \mathrm{min}$ in $4 \mathrm{~min}$, separated by the analysis column at a flow rate of $300 \mathrm{~nL} / \mathrm{min}$, and transferred to the MS system. The MS gradient consisted of $5 \%$ buffer B (95\% acetonitrile, $0.1 \%$ formic acid) for $5 \mathrm{~min} ; 5$ to $35 \%$ buffer B for 35 min; 35 to $80 \%$ buffer B for 2 min; $80 \%$ buffer B for 4 min; and $5 \%$ buffer B for 1 min. The mass spectrometer analysis was performed as previously described (Sun et al., 2017).

\section{Proteomic Data Analysis}

The MS datum was collected using Analyst QS 2.0 (Applied Biosystems/MDS Sciex) and processed using Proteome Discoverer software (Version 1.2, Thermo Fisher Scientific Inc., Waltham, MA) to generate the peak list. Protein identification was carried out using Mascot 2.3.02 (Matrix Science, London, UK). For iTRAQ quantification, a mass tolerance of $0.05 \mathrm{Da}$ (ppm) was permitted for the intact peptide masses and 0.1 Da for fragmented ions, with allowance for one missed cleavage in the trypsin digests. (The variability of reporter ion ratios for peptides assigned to each protein is shown in Supplemental Figure S1C; https://doi.org/10.3168/jds.2018-14594). For peptide searching, the parameters were set as follows: variable
modifications-Gln- $>$ pyro-Glu (N-term Q), Oxidation $(\mathrm{M})$, Deamidated (NQ); fixed modifications-Carbamidomethyl (C), iTRAQ 8-plex (N-term), iTRAQ 8-plex (K); database-BioProject: PRJNA419050 (2,133 sequences). Only peptides with significance scores $(\geq 20)$ at the $99 \%$ confidence interval by a Mascot probability analysis were identified to reduce the probability of false peptide identification. Proteins that changed more than 1.2-fold with a $P$-value less than 0.05 between the stressed and control samples were deemed significantly expressed proteins. Analysis with cluster of orthologous groups of proteins was conducted according to the NCBI database (http://www.ncbi.nlm.nih.gov/ COG/). The metabolic pathway analysis of qualitative peptides was performed based on the KEGG database (KEGG; http://www.kegg.jp/). The proteomics raw datum used in this study has been deposited in the ProteomeXchange database with the accession number PXD008255.

\section{Quantitative Real-Time PCR Assay}

Total RNA were extracted with ZR RNA MiniPrep (Zymo Research, Irvine, CA). The RNA were reversed transcribed into first-strand cDNA with RevertAid First Strand cDNA Synthesis Kit (Thermo Fisher Scientific). The transcriptions of genes were detected by the LightCycler 480 Real-Time PCR System (Roche Diagnostics Ltd., Mannheim, Germany). The qPCR reactions were performed in $20-\mu \mathrm{L}$ volumes consisting of $5 \mu \mathrm{L}$ of cDNA $(100 \mathrm{ng}), 10 \mu \mathrm{L}$ of LightCycler 480 SYBR Green I Master Mix (Roche Diagnostics Ltd.), $1 \mu \mathrm{L}$ of each primer (final concentration was $0.5 \mu M$ ), and $3 \mu \mathrm{L}$ of RNase-Free water. The PCR program ran as follows: preincubation at $95^{\circ} \mathrm{C}$ for $5 \mathrm{~min}$ followed by 45 cycles of $95^{\circ} \mathrm{C}$ for $10 \mathrm{~s}, 55^{\circ} \mathrm{C}$ for $10 \mathrm{~s}$, and $72^{\circ} \mathrm{C}$ for 20 $\mathrm{s}$; for acquisition mode, a melting curve cycle of $95^{\circ} \mathrm{C}$ for $5 \mathrm{~s}, 65^{\circ} \mathrm{C}$ for $1 \mathrm{~min}$, and $97^{\circ} \mathrm{C}$ was employed. The $16 \mathrm{~S}$ rRNA gene was the endogenous control gene used for normalization. Triplicate technical replicates were carried out, and differences in the relative expression levels were calculated with the $2^{-\Delta \Delta \mathrm{CT}}$ method. Furthermore, the primers used for quantitative real-time (qRT) PCR are shown in Supplemental Table S1 (https://doi.org/ 10.3168/jds.2018-14594).

\section{Statistical Analysis}

To evaluate the statistical significance of cell density, Student's $t$-test was performed. In proteomic analysis, statistical analysis was carried out using $P$-values calculated by Student's t-test. 


\section{RESULTS AND DISCUSSION}

\section{Identification of Properties of L. lactis F44 Under Low-pH and Lactate Stress}

To address the responses of acid and lactate in L. lactis F44, we investigated the growth performance in the short term of single and cross-stress with 1, 2, and $3 \%$ lactic acid and $\mathrm{pH} 4.0,5.0,6.0$, and 7.0 with each percentage of lactic acid (Figure 1), and the whole growth performance from 0 to $12 \mathrm{~h}$ is shown in Supplemental Figure S2 (https://doi.org/10.3168/jds.2018-14594). Under a certain concentration of lactic acid, the viability of cells decreased as the $\mathrm{pH}$ decreased. The growth rate was reduced at $1 \%$ lactic acid, whereas the cell density maintained an increasing trend (Figure 1A). At $2 \%$ lactic acid (Figure 1B), the growth ability of cells in $\mathrm{pH} 7.0$ and 6.0 was weakened; the cell density in $\mathrm{pH} 5.0$ slightly increased in $0.5 \mathrm{~h}$ but decreased thereafter; the growth of cells in $\mathrm{pH} 4.0$ was prominently suppressed compared with $\mathrm{pH} 7.0$ at $2 \mathrm{~h}(P=0.0005)$. A decrease in $\mathrm{pH}$ induced an enormous inhibitory effect on cells in $3 \%$ lactic acid. The cell density in $\mathrm{pH} 6.0$ started to reduce after $0.5 \mathrm{~h}$, and the inhibitory effect increased as $\mathrm{pH}$ value decreased (Figure 1C). At $1 \mathrm{~h}$, the strains showed significant differences $(P<0.05)$ in viability under various cross-stress conditions, and the survival rate was greater than or equal to mortality in most samples. These results verified that cross-stress of low$\mathrm{pH}$ and lactate could severely affect cell growth, and $1 \mathrm{~h}$ was an opportune time for investigating cellular response. To gain further insights on cross-stress effects of $\mathrm{H}^{+}$and lactate, we investigated cellular response through quantitative proteomic analysis of 3 groups after $1 \mathrm{~h}$ of stress: L0P4 and L0P5 for acid stress; L2P7 and L3P7 for lactate stress; and L2P4, L2P5, L3P4, and L3P5 for cross-stress.

\section{Overview of Proteomic Analysis}

In the iTRAQ liquid chromatography-electrospray ionization-tandem MS proteomic analysis, a total of 330,363 spectra were acquired. After filtering data, the qualified spectra were matched to 1,365 proteins - approximately $64 \%$ of the 2,133 predicted proteins in the L. lactis F44 genome. The protein mass distribution showed good coverage (Supplemental Figure S1A; https://doi.org/10.3168/jds.2018-14594), $73 \%$ of the proteins were identified with more than $10 \%$ of the sequence coverage and $49 \%$ were with $20 \%$ of the sequence coverage (Supplemental Figure S1B; https:// doi.org/10.3168/jds.2018-14594).

A proteomic comparison analysis was performed between different conditions: L0P4 versus L0P5 for acid
A

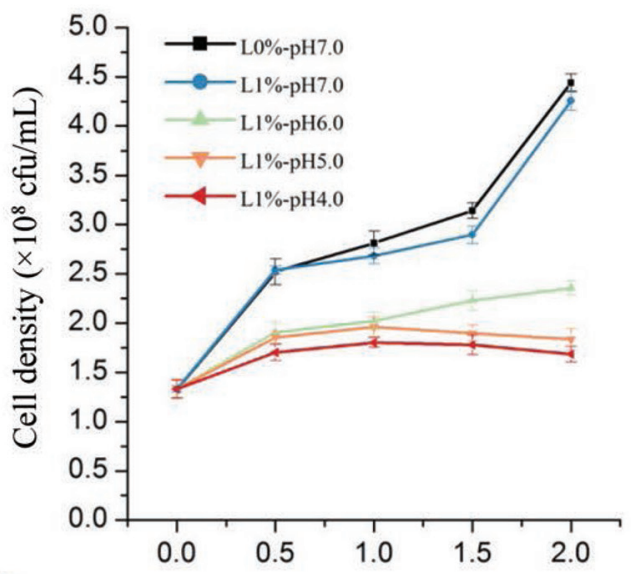

B

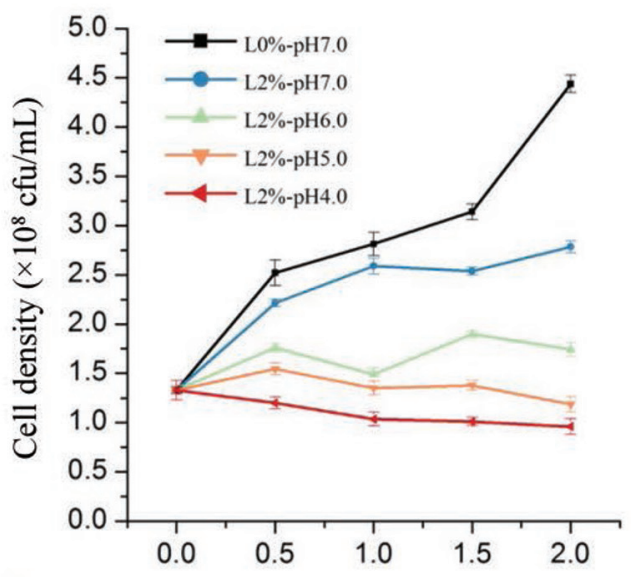

C

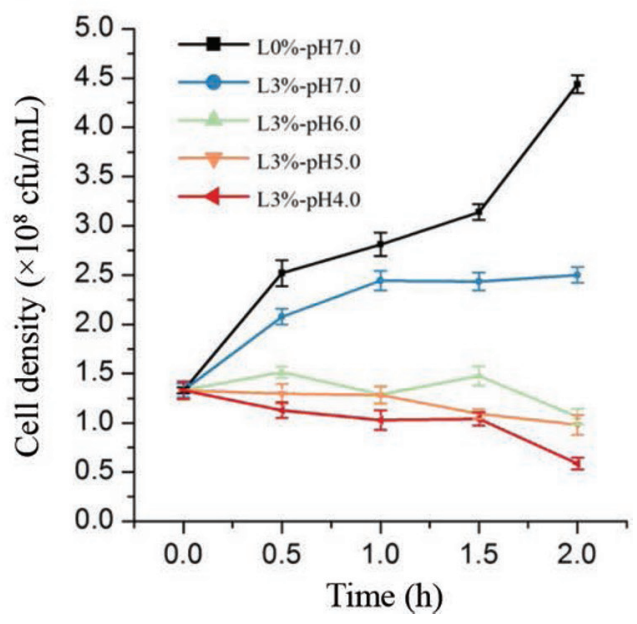

Figure 1. Growth properties assay of Lactococcus lactis F44 under diverse low-pH and lactate stresses. (A) Cell density under 1\% lactate (L) stress with $\mathrm{pH}$ values ranging from 4.0 to 7.0. (B) Cell density under $2 \%$ lactate stress with $\mathrm{pH}$ values ranging from 4.0 to 7.0 . (C) Cell density under $3 \%$ lactate stress with $\mathrm{pH}$ values ranging from 4.0 to 7.0. Lactococcus lactis $\mathrm{F} 44$ at $\mathrm{pH} 7.0$ with no addition of lactate was used as a control. Error bars indicate the standard deviation of 3 independent experiments. Color version available online. 
stress; L3P7 versus L2P7 for lactate stress; L2P5 versus L2P7, L2P5 versus L0P5, L3P5 versus L3P7, L3P5 versus L0P5, L2P4 versus L2P7, L2P4 versus L0P4, L3P4 versus L3P7, and L3P4 versus L0P4 for cross-stress. Significantly changed proteins were selected by using a cutoff of 1.2 -fold change and a $P$-value less than 0.05 . Ten comparisons of the number of the significantly changed proteins are shown in Figure 2A. According to the analysis, the amount of significantly changed proteins in 4 comparison samples, L2P4 versus L2P7 (448), L2P4 versus L0P4 (394), L3P4 versus L3P7 (369), and L3P4 versus L0P4 (352), was greater than that of the other samples. Cross-stress had a greater effect than single stress, and the low $\mathrm{pH}$ that influences the dissociation degree of lactic acid was the determinant factor within the cross-stress conditions. Undissociated lactic acid can easily penetrate the cell membrane and reach the cytoplasm where it dissociates, lowering the cytoplasmic $\mathrm{pH}$. Moreover, according to the concentration of undissociated lactic acid (Supplemental Table S2; https://doi.org/10.3168/jds.2018-14594), we categorized 8 comparison samples into 2 groups: the lower concentration group with approximately $6.7 \%$ undissociated lactic acid (L2P5 vs. L2P7, L2P5 vs. L0P5, L3P5 vs. L3P7, and L3P5 vs. L0P5) and the higher concentration group with approximately $42.0 \%$ undissociated lactic acid (L2P4 vs. L2P7, L2P4 vs. L0P4, L3P4 vs. L3P7, and L3P4 vs. L0P4). The overlapped proteins among these groups were illustrated in Venn diagram (Venny 2.1). A total of 104 proteins (in the higher concentration group, Figure 2B) and 15 proteins (in the lower concentration group, Figure 2C) were significantly changed in every comparison of each group. To validate our proteomics results, we selected 8 of the differentially expressed proteins and evaluated their transcriptional levels via qRT-PCR. According to the comparison of qRT-PCR and proteomic results, a positive correlation was still observed even though slight differences existed (Supplemental Table S3; https://doi .org/10.3168/jds.2018-14594), suggesting the proteomic results were of good quality.

\section{Effects of Cross-Stress on General Stress Response and DNA Repair}

Many molecular chaperones and proteases that are related to protein protection were changed significantly $(P<0.05)$ in response to lactic acid stress in L. lactis F44 (Supplemental Table S4; https://doi.org/10.3168/ jds.2018-14594). In L2P4 versus L2P7, L3P4 versus L3P7, L2P4 versus L0P4, and L3P5 versus L3P7, GroES (10-kDa chaperonin) was upregulated. Furthermore, the GroEL/ES complex is responsible for appropriate protein folding and frequently participates in response to diverse stresses. The transcription of groES is also increased with exposure to bile salts or acidic environments (Wu et al., 2012; An et al., 2014). Analogously, chaperone GroEL upregulation preserves protein function under acid stress in Strep. thermophilus (Arena et al., 2006). In addition, molecular chaperone Hsp33 ( $\mathrm{HslO})$ and copper chaperone (CopZ) were more abundant at L2P4 versus L2P7, L2P4 versus L0P4, L3P4 versus L3P7, and L3P4 versus L0P4. In Streptococcus mutans, the $\triangle \operatorname{cop} Y A Z$ strain reduced cell viability under acid stress, indicating that CopYAZ contributed to the acid tolerance response of $S$. mutans (Singh et al., 2015). Moreover, Clp ATPase, ClpC and ClpX, which either prevent protein unfolding or promote disaggregation (Saibil, 2013; Frees et al., 2014), were downregulated in a relatively higher concentration of undissociated lactic acid conditions (L2P4 vs. L2P7 and L2P4 vs. L0P4). Furthermore, serine protease is a class of proteins that cleave macromolecule proteins. In this study, exported serine protease HtrA was upregulated in $\mathrm{L} 2 \mathrm{P} 4$ versus $\mathrm{L} 2 \mathrm{P} 7, \mathrm{~L} 2 \mathrm{P} 4$ versus $\mathrm{L} 0 \mathrm{P} 4, \mathrm{~L} 3 \mathrm{P} 4$ versus L3P7, and L3P4 versus L0P4, whereas it was repressed at L2P5 versus L2P7 and L2P5 versus L0P5. Previous studies have found that HtrA plays a vital role in the degradation of misfolded proteins for the maintenance of physiological homeostasis of bacteria against various environmental stresses, especially acid stress (Kang et al., 2010). Similarly, serine protease Rv3671c was confirmed to protect Mycobacterium tuberculosis from oxidative and acidic stress by degrading unfolded proteins (Biswas et al., 2010). These results suggested that a high concentration of undissociated lactic acid could facilitate the degradation of damaged proteins.

The proteomic analysis suggested that a relatively high concentration of undissociated lactic acid (L2P4 vs. L2P7 and L2P4 vs. L0P4) restrained the expressions of DNA repair proteins, such as DNA polymerase III subunit $\beta$ DnaN, replication initiation protein DnaA, DNA mismatch repair protein (DYH_g2188), and NAD-dependent DNA ligase LigA. In the contrary, YqgF family resolvase YbeB, single-stranded DNAbinding protein SsbB2, and exodeoxyribonuclease VII small subunit XseB that are related to mismatch repair were upregulated in L3P4 versus L0P4 and L2P4 versus L0P4.

\section{Effect of Cross-Stress on Synthesis of Cell Wall and Lipid Metabolism}

The cell wall is the first barrier that withstands environmental stress, and a combined action of peptidoglycan (PG) synthesizing enzymes and hydrolases maintains a balance between cell wall rigidity and flexibility for optimal cell growth and separation under 
environmental changes. Cell wall genes were unchanged in the low concentration of undissociated lactic acid; however, they were significantly changed $(P<0.05)$ with the high concentration of undissociated lactic acid, including $\mathrm{L} 2 \mathrm{P} 4$ versus $\mathrm{L} 2 \mathrm{P} 7, \mathrm{~L} 2 \mathrm{P} 4$ versus $\mathrm{L} 0 \mathrm{P} 4$, L3P4 versus L0P4, and L3P4 versus L3P7. As shown in Figure 3, the proteins that are involved in the first stage of PG synthesis, such as MurA1 (UDP- $N$-acetylglucosamine 1-carboxyvinyltransferase), MurD (UDP$\mathrm{N}$-acetylmuramoyl-L-alanyl-D-glutamate synthetase),
MurE (UDP- $N$-acetylmuramoylalanyl-D-glutamate-2,6diaminopimelate ligase), and Ddl (D-alanine-D-alanine ligase), were downregulated in the comparisons of $\mathrm{L} 2 \mathrm{P} 4$ versus $\mathrm{L} 2 \mathrm{P} 7$ and $\mathrm{L} 2 \mathrm{P} 4$ versus $\mathrm{L} 0 \mathrm{P} 4$. The second-stage proteins MurG (UDP diphospho-muramoylpentapeptide beta- $N$-acetylglucosaminyltransferase) and MraY (phospho- $N$-acetylmuramoyl-pentapeptide-transferase) were upregulated 1.41-fold and 1.52-fold in L2P4 versus L0P4 as well as 1.75-fold and 1.42-fold in L3P4 versus L0P4. For the third stage of PG synthesis,
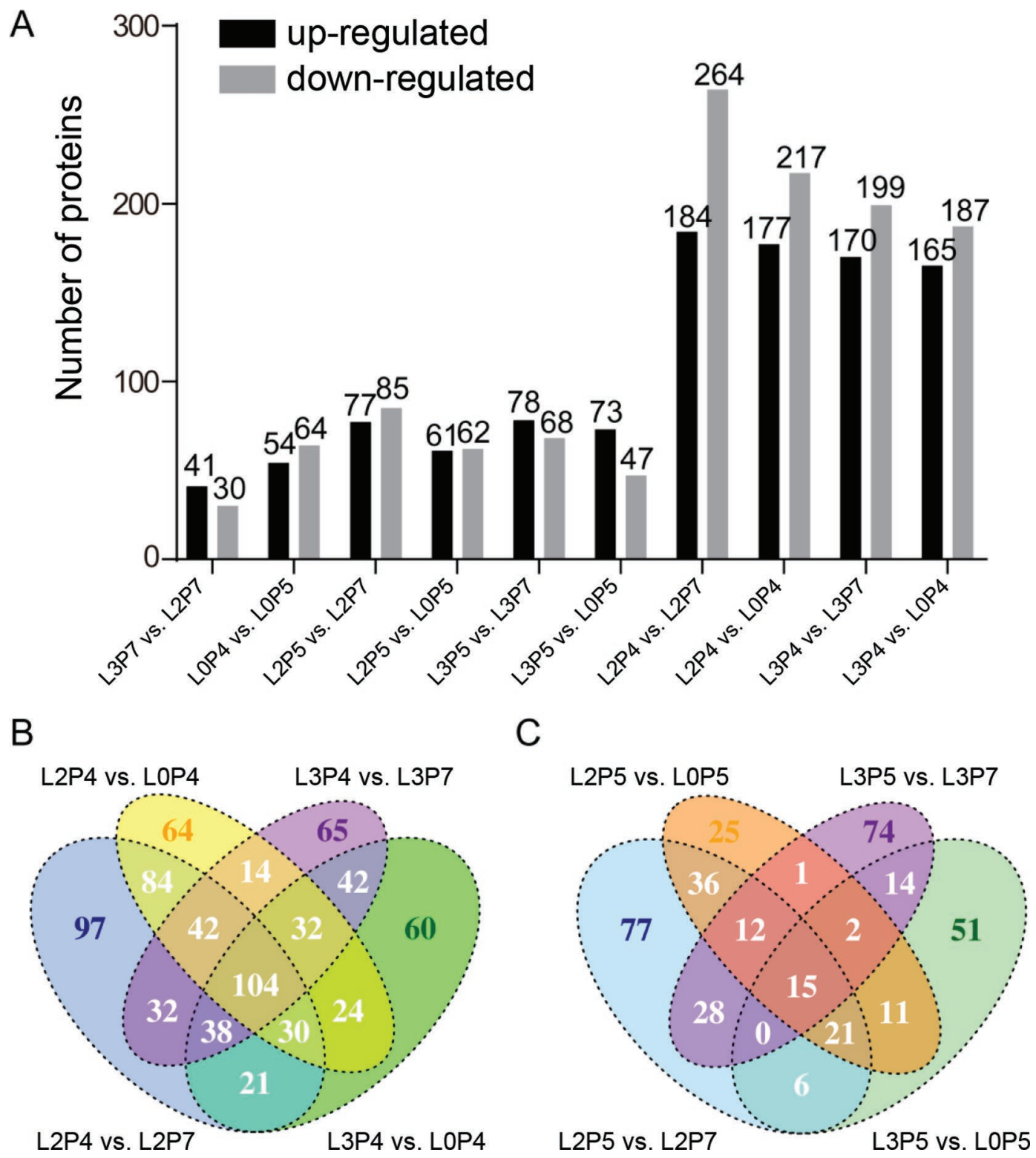

Figure 2. Profile of the significantly expressed proteins of Lactococcus lactis F44 in response to various low-pH and lactate stresses. (A) The number of the significantly expressed proteins at diverse stress challenges. (B) Comparison of the number of differentially expressed proteins in L2P4 versus L0P4, L3P4 versus L0P4, L2P4 versus L2P7, and L3P4 versus L3P7. (C) Comparison of the number of differentially expressed proteins in $\mathrm{L} 2 \mathrm{P} 5$ versus $\mathrm{L} 0 \mathrm{P} 5, \mathrm{~L} 3 \mathrm{P} 5$ versus $\mathrm{L} 0 \mathrm{P} 5, \mathrm{~L} 2 \mathrm{P} 5$ versus $\mathrm{L} 2 \mathrm{P} 7$, and $\mathrm{L} 3 \mathrm{P} 5$ versus $\mathrm{L} 3 \mathrm{P} 7$. $\mathrm{L} 0 \mathrm{P} 5=\mathrm{pH} 5.0$ without lactic acid, $\mathrm{L} 0 \mathrm{P} 4=\mathrm{pH}$ 4.0 without lactic acid, $\mathrm{L} 2 \mathrm{P} 7=2 \%$ lactic acid with $\mathrm{pH} 7.0, \mathrm{~L} 3 \mathrm{P} 7=3 \%$ lactic acid with $\mathrm{pH} 7.0, \mathrm{~L} 2 \mathrm{P} 5=2 \%$ lactic acid with $\mathrm{pH} 5.0, \mathrm{~L} 2 \mathrm{P} 4=$ $2 \%$ lactic acid with $\mathrm{pH} 4.0, \mathrm{~L} 3 \mathrm{P} 5=3 \%$ lactic acid with $\mathrm{pH} 5.0$, and $\mathrm{L} 3 \mathrm{P} 4=3 \%$ lactic acid with $\mathrm{pH}$ 4.0. Proteins with at least a 1.2 -fold change are shown; adjusted $P<0.05$ for all data selected. Color version available online. 
PbpX (cell division specific D,D-transpeptidase FtsI) and DacB (D-alanyl-D-alanine carboxypeptidase) were increased at L2P4 versus L2P7, and MrcA (Pbp1A, penicillin-binding protein $1 \mathrm{~A}$ ) was induced at L3P4 versus L3P7. Overall, these results indicated that the synthesis of UDP-MurNAc-pentapeptide was repressed, whereas the formation of lipid II and the crosslink of PG polymers were increased in response to the high concentration of undissociated lactic acid. Moreover, HasC (UTP-glucose-1-phosphate uridylyltransferase) was activated at $\mathrm{L} 2 \mathrm{P} 4$ versus $\mathrm{L} 2 \mathrm{P} 7, \mathrm{~L} 3 \mathrm{P} 4$ versus $\mathrm{L} 3 \mathrm{P} 7$, $\mathrm{L} 2 \mathrm{P} 4$ versus $\mathrm{L} 0 \mathrm{P} 4, \mathrm{~L} 3 \mathrm{P} 4$ versus $\mathrm{L} 0 \mathrm{P} 4$, and $\mathrm{L} 3 \mathrm{P} 5$ versus L3P7 (1.80-fold, 1.52-fold, 1.46-fold, 1.28-fold, and 1.23 -fold, respectively). Similar to our results, HasC was upregulated during acid adaptation in M17 and SA medium in L. lactis MG1363 (Budin-Verneuil et al., 2005). In addition, peptidoglycan hydrolases, Nacetylmuramidase (AcmA and AcmD), and endopeptidase YjgB were upregulated in L3P4 versus L3P7. The expression of AcmD was enhanced 3.74-fold in L2P4 versus L2P7, and YjgB was 4.69-fold more abundant in L3P4 versus L3P7. Similar to AcmA, AcmD consists of an active site domain in the N-terminal and a peptidoglycan-binding domain containing 3 LysM domains in the C-terminal (Steen et al., 2005). The LysM domain of AcmD interacted strongly with the cell wall at $\mathrm{pH} 4.0$ and contributed to cell separation and autolysis (Visweswaran et al., 2013). Furthermore, YjgB is the protein cleaving the bond of D-Gln and L-Lys in the pentapeptide chain of L. lactis PG (Redko et al., 2007). These observations suggest that a higher concentration of undissociated lactic acid has accelerated PG hydrolysis and cells autolysis.

In lipid metabolism, 4-phosphopantetheinyl transferase AcpS was more abundant in $\mathrm{L} 2 \mathrm{P} 4$ versus $\mathrm{L} 0 \mathrm{P} 4$, L3P4 versus L3P7, and L3P4 versus L0P4 and plays a crucial role in activating 2 distinct acyl carrier proteins in fatty acid synthase systems (Morgan-Kiss and Cronan, 2004). In this study, acyl carrier protein YdiD was also activated at $\mathrm{L} 2 \mathrm{P} 4$ versus $\mathrm{L} 2 \mathrm{P} 7, \mathrm{~L} 2 \mathrm{P} 4$ versus $\mathrm{L} 0 \mathrm{P} 4$, L3P4 versus L3P7, and L3P4 versus L0P4. Moreover, (3R)-hydroxymyristoyl-acyl carrier protein dehydratase

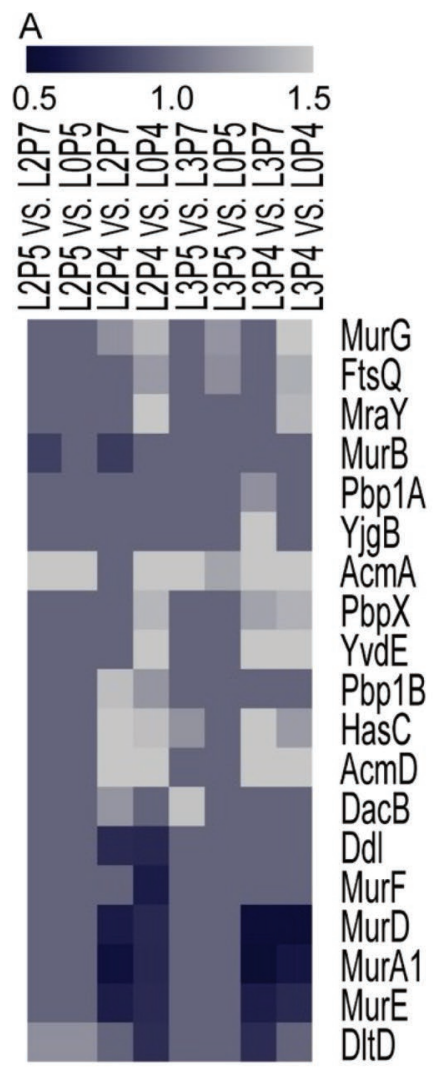

B

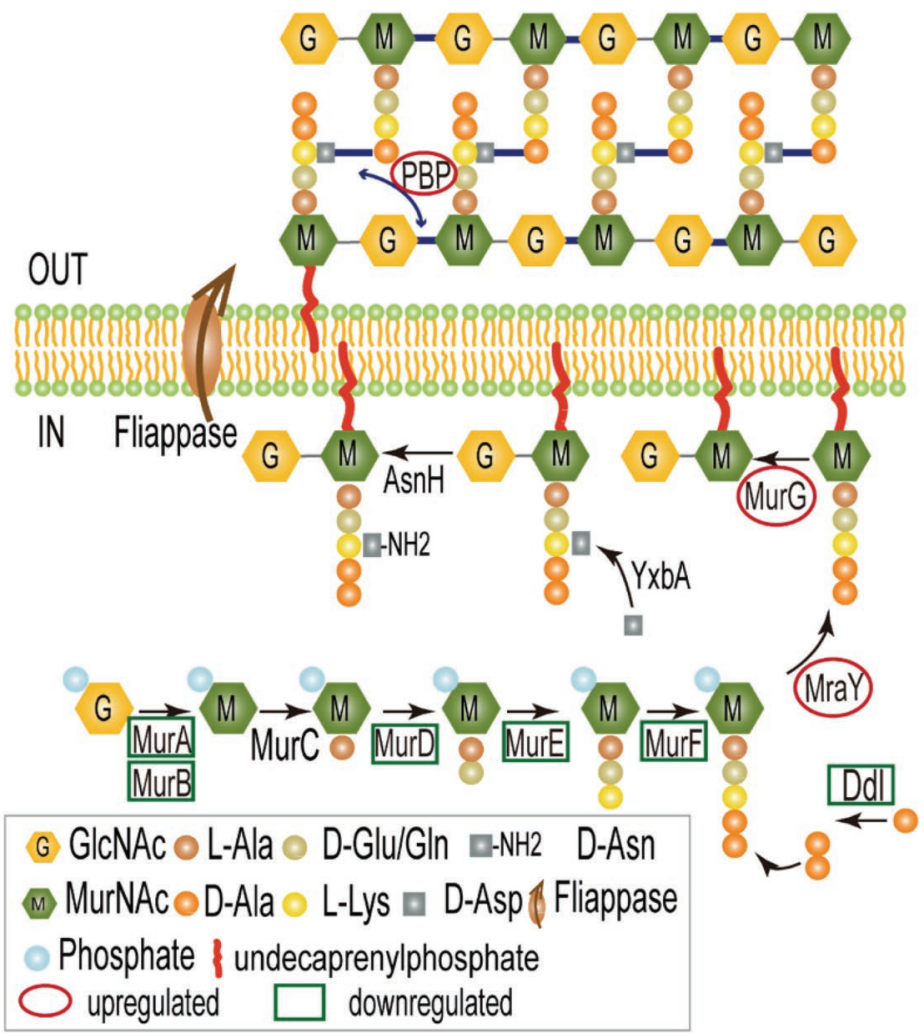

Figure 3. Expression of proteins involved in peptidoglycan biosynthesis under cross-stress in Lactococcus lactis F44. (A) Heat map of L. lactis F44 peptidoglycan biosynthesis genes differently expressed (on a $\log _{2}$ scale, $P<0.05$ ) under cross-stress. L0P5 $=\mathrm{pH} 5.0$ without lactic acid, $\mathrm{L} 0 \mathrm{P} 4=\mathrm{pH} 4.0$ without lactic acid, $\mathrm{L} 2 \mathrm{P} 7=2 \%$ lactic acid with $\mathrm{pH} 7.0, \mathrm{~L} 3 \mathrm{P} 7=3 \%$ lactic acid with $\mathrm{pH} 7.0, \mathrm{~L} 2 \mathrm{P} 5=2 \%$ lactic acid with $\mathrm{pH} 5.0, \mathrm{~L} 2 \mathrm{P} 4=2 \%$ lactic acid with $\mathrm{pH} 4.0, \mathrm{~L} 3 \mathrm{P} 5=3 \%$ lactic acid with $\mathrm{pH} 5.0$, and $\mathrm{L} 3 \mathrm{P} 4=3 \%$ lactic acid with $\mathrm{pH} 4.0$. (B) Simple scheme of the peptidoglycan biosynthesis pathway. The upregulated proteins are in circles. The downregulated proteins are in rectangles. The proteins with no changes are in black font. Color version available online. 
FabZ2 was upregulated in those comparisons, especially in L3P4 versus L3P7, where it displayed a 3.35-fold remarkable increase. FabZ is a universally expressed component for the elongation cycles of saturated and unsaturated fatty acid biosynthesis in type II fatty acid synthase (Zhang et al., 2008) and is associated with stress response (Jeamton et al., 2008; Liang et al., 2013). In this study, FabG1 (3-ketoacyl-ACP reductase) was increased by 1.21 -fold at L3P 4 versus L3P7. Furthermore, we observed that the expression of cyclopropane-fatty-acyl-phospholipid synthase $\mathrm{Cfa}$ was reduced at $\mathrm{L} 2 \mathrm{P} 4$ versus $\mathrm{L} 2 \mathrm{P} 7, \mathrm{~L} 3 \mathrm{P} 4$ versus L3P7, and L3P4 versus L0P4 (0.41, 0.37, and 0.44). Despite being recognized as pivotal in response to the change of environment in many bacteria, Cfa was proven by To et al. to be nonessential for L. lactis strain survival in an acidic environment (To et al., 2011).

\section{Cross-Stress Represses Carbohydrate and Energy Metabolism}

Carbohydrate and energy metabolism were generally repressed under cross-stress (Figure 4) because lactate induced the feedback inhibition of the glycolytic pathway and strains tried to compensate for energy deficiency by increasing the intake of glucose and $\beta$-glucoside. In the phosphate transfer systems (PTS), the most efficient sugar uptake systems, phosphocarrier protein $\mathrm{PtsH}$, cellobiose-specific transporter subunit IIA PtcA, and $\beta$-glucoside-specific transporter subunit IIA YedE, were upregulated in L2P4 versus L0P4 and L3P4 versus L3P7. Previous studies have found that glucose is transported and subsequently phosphorylated by mannose PTS, cellobiose PTS, and the nonPTS permease/glucokinase pathway in L. lactis (Len et al., 2004; Pool et al., 2006; Castro et al., 2009). The phosphocarrier protein $\mathrm{Hpr}$ ( $\mathrm{PtsH}$ ) was also shown to be more abundant in acid-stressed $L$. casei Zhang ( $\mathrm{Wu}$ et al., 2012) and L. plantarum 423 (Heunis et al., 2014). Nevertheless, the proteins ScrA (sucrose-specific phosphotransferase system, enzyme IIBCA), FruA (PTS system fructose-specific transporter subunit IIABC), and PtnD (mannose-specific PTS system component IID), which are involved in the uptake of sucrose, fructose, and mannose, respectively, were decreased in L3P4 versus L3P7 and L3P4 versus L0P4. Proteins ScrB (sucrose-6-phosphate hydrolase) and ScrK (fructokinase) were also repressed in L3P4 versus L3P7 and L3P4 versus L0P4. These alterations suggested that the uptake and metabolism of sucrose were influenced under a high concentration of undissociated lactic acid. The enzymes that are involved in glycogen metabolism, such as glucose-1-phosphate adenylyltransferase GlgD, glycogen synthase GlgA, and glycogen phosphorylase
GlgP, were suppressed at L2P4 versus L2P7 and L2P4 versus L0P4. We presumed that the carbon source of bacteria for the synthesis of glycogen was decreased, because the majority of carbon sources were used for the maintenance of bacterial growth and acid resistance under a high concentration of undissociated lactic acid cross-stress. In addition, the enzymes GlmM (phosphoglucosamine mutase) and GlmS (glucosamine-fructose6-phosphate aminotransferase) that are associated with UDP-GlcNAc, which is the precursor of peptidoglycan synthesis, were downregulated in L2P4 versus L2P7.

Glycolysis plays a vital role in the supply of energy in L. lactis. Phosphoglycerate mutase YjhF, which is involved in the glycolysis pathway, was upregulated by 1.57 -fold, whereas the phosphopyruvate hydratase EnoA and glyceraldehyde 3-phosphate dehydrogenase GapA were downregulated at L2P4 versus L0P4. In L3P5 versus L3P7, 6-phosphofructokinase Pfk was 1.26 -fold more abundant. In addition, pyruvate-formate lyase Pfl, which participates in pyruvate metabolism, was increased at L2P5 versus L0P5 and L3P5 versus L0P5. To reduce lactic acid injury, L-lactate dehydrogenase Ldh, an enzyme that forms L-lactate from pyruvate, was repressed (0.68) in L3P4 versus L0P4. Furthermore, L-lactate oxidase LctO, which facilitates the conversion of lactate to pyruvate, was more abundant in $\mathrm{L} 2 \mathrm{P} 4$ versus $\mathrm{L} 2 \mathrm{P} 7, \mathrm{~L} 2 \mathrm{P} 4$ versus $\mathrm{L} 0 \mathrm{P} 4, \mathrm{~L} 3 \mathrm{P} 4$ versus L3P7, and L3P4 versus L0P4. Proteins related to tricarboxylic acid cycle, isocitrate dehydrogenase Icd, aconitate hydratase CitB, citrate synthase GltA, and pyruvate carboxylase PycA, were downregulated at $\mathrm{L} 2 \mathrm{P} 4$ versus L2P7. In addition, most ATP synthase subunits, such as AtpA, AtpH, AtpG, and AtpB, were reduced under cross-stress in comparison with single stress.

\section{Effects of Cross-Stress on AA Metabolism}

In LAB, AA catabolism participates in a series of physiological processes such as intracellular $\mathrm{pH}$ regulation, metabolic energy generation, and resistance to stresses (Fernández and Zúñiga, 2006). Increasing the intracellular $\mathrm{pH}$ by arginine deiminase is a general method in LAB. The arginine deiminase pathway includes arginine deiminase, ornithine carbamoyltransferase, and carbamate kinase. In this system, the production of $\mathrm{NH}_{3}$, which can raise the internal $\mathrm{pH}$ by combination with $\mathrm{H}^{+}$to generate $\mathrm{NH}_{4}^{+}$, increased the acid tolerance of cells (Cotter and Hill, 2003). As shown in Figure 5 , ornithine carbamoyltransferase ArcB and carbamate kinase $\mathrm{ArcC} 2$ and $\mathrm{ArcC} 3$, which are associated with the arginine deiminase pathway that induced $\mathrm{NH}_{3}$ accumulation, were upregulated in L2P4 versus L0P4. Moreover, glutamine synthetase GlnA, which consumes 
$\mathrm{NH}_{3}$, was downregulated. The glutamate decarboxylase pathway is another important strategy against the acid stress of LAB (De Biase and Pennacchietti, 2012). Nevertheless, GadB (glutamate decarboxylase) was downregulated in L2P4 versus L0P4 (0.64), L3P4 versus L0P4 (0.63), and L3P4 versus L3P7 (0.53).

Amino acid transportation and synthesis were changed under cross-stresses (Figure 5). The abundance of tryptophan synthase $\alpha$ chain TrpA (DYH_g0835) was increased in L2P4 versus L2P7 (1.52-fold), L2P4 versus L0P4 (1.66-fold), L3P4 versus L3P7 (1.73-fold), and L3P4 versus L0P4 (1.62-fold). This enzyme can not only convert indole-3-glycerol-P to D-glyceraldehyde 3-phosphate and alkaline indole, but also transform L-serine to L-tryptophan. Furthermore, serine hydroxymethyltransferase GlyA, which converts glycine to Lserine, was enhanced at L2P4 versus L2P7 (1.67-fold) and L3P4 versus L0P4 (1.55-fold). Therefore, the metabolic flux from glycine to L-tryptophan via serine was improved. L-Serine dehydratase SdaA, which can generate $\mathrm{NH}_{3}$ by catalyzing L-serine to pyruvate, was slightly upregulated at the low concentration of undissociated lactic acid stress (L2P5 vs. L2P7, L2P5 vs. L0P5, and L3P5 vs. L0P5) but was downregulated at L2P4 versus L0P4. In addition, CysK (cysteine synthase) and CysM (cysteine synthase A), which are associated with the synthesis of cysteine, were increased under the majority of cross-stresses. A previous study also showed that glutathione could protect $L$. lactis against acid stress (Zhang et al., 2007).

In $\mathrm{LAB}$, a proteolytic system consisting of the proteinases related to cell envelope, membrane-bound transport systems, and several cytoplasmic peptidases contributes to the release of free AA from medium.

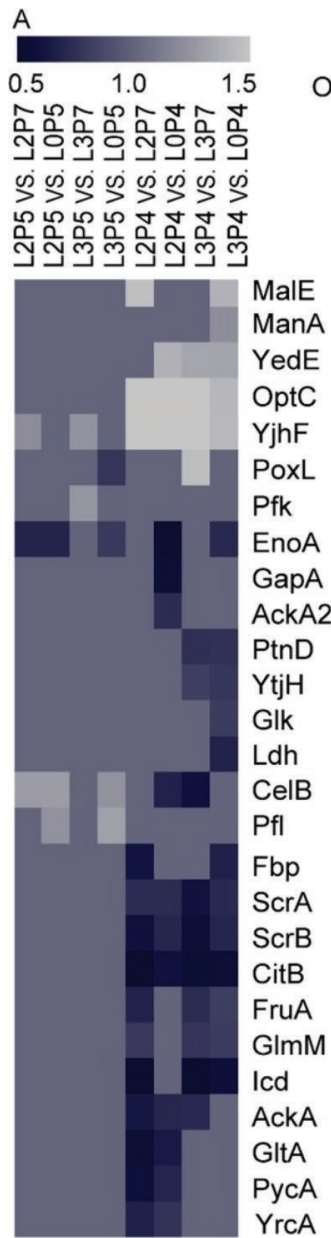

B

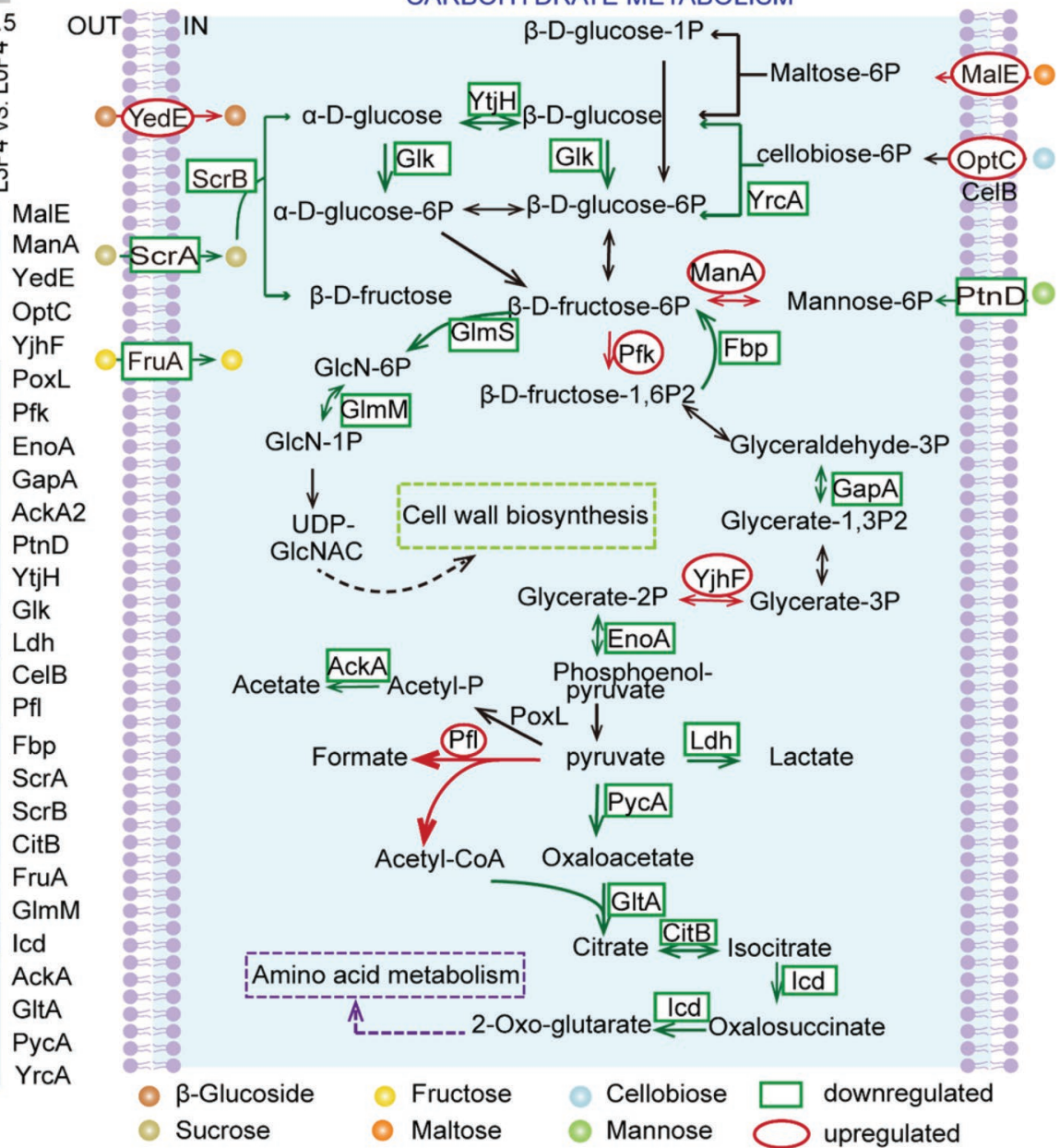

Figure 4. The simplified pathways of carbohydrate metabolism under cross-stress in Lactococcus lactis F44. (A) Heat map of L. lactis F44 carbohydrate metabolism genes differently expressed (on a $\log _{2}$ scale, $P<0.05$ ) under cross-stress. L0P5 $=\mathrm{pH} 5.0$ without lactic acid, L0P4 $=$ $\mathrm{pH} 4.0$ without lactic acid, L2P7 $=2 \%$ lactic acid with $\mathrm{pH} 7.0, \mathrm{~L} 3 \mathrm{P} 7=3 \%$ lactic acid with $\mathrm{pH} 7.0, \mathrm{~L} 2 \mathrm{P} 5=2 \%$ lactic acid with pH 5.0, L2P4 $=2 \%$ lactic acid with $\mathrm{pH} 4.0, \mathrm{~L} 3 \mathrm{P} 5=3 \%$ lactic acid with $\mathrm{pH} 5.0$, and $\mathrm{L} 3 \mathrm{P} 4=3 \%$ lactic acid with $\mathrm{pH} 4.0$. (B) Simple scheme of carbohydrate metabolism. The upregulated proteins are in circles. The downregulated proteins are in rectangles. Color version available online. 
Amino acid ABC transporter substrate-binding protein YvdF was upregulated in L3P4 versus L7P4, L2P4 versus L0P4, and L3P4 versus L3P7, and spermidine/putrescine $\mathrm{ABC}$ transporter permease protein PotC was enhanced in $\mathrm{L} 2 \mathrm{P} 4$ versus L2P7, L2P5 versus L2P7, and L3P4 versus L3P7. The substrate-binding protein PotD was upregulated by 1.39 -fold at L2P5 versus L0P5. Polyamines, putrescine, spermidine, and spermine are essential for cell proliferation and modulatd the protein synthesis by changing the RNA structure and the assembly of 30 S ribosomal subunits (Igarashi and Kashiwagi, 2010, 2015). Furthermore, the spermidine-preferential uptake system is composed of 4 proteins PotABCD, and intracellular spermidine serves as a physiological blocker of inward rectifier $\mathrm{K}^{+}$channels that control the resting membrane potential. In addition, a previous study found that PotD induced the SOS system gene expression and biofilm formation to cope with the changing environment (Zhang et al., 2013). Thus, we presumed that the spermidine-preferential uptake system might contribute to cellular resistance against cross-stress. Glutamine ABC transporter ATP-binding protein $\mathrm{GlnQ}$ was more abundant in $\mathrm{L} 2 \mathrm{P} 4$ versus $\mathrm{L} 2 \mathrm{P} 7$, L2P4 versus L0P4, and L3P4 versus L0P4. Moreover,

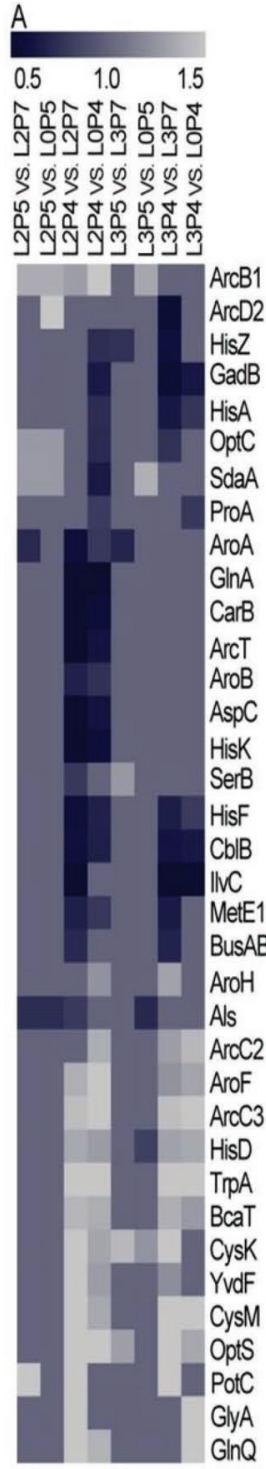

B

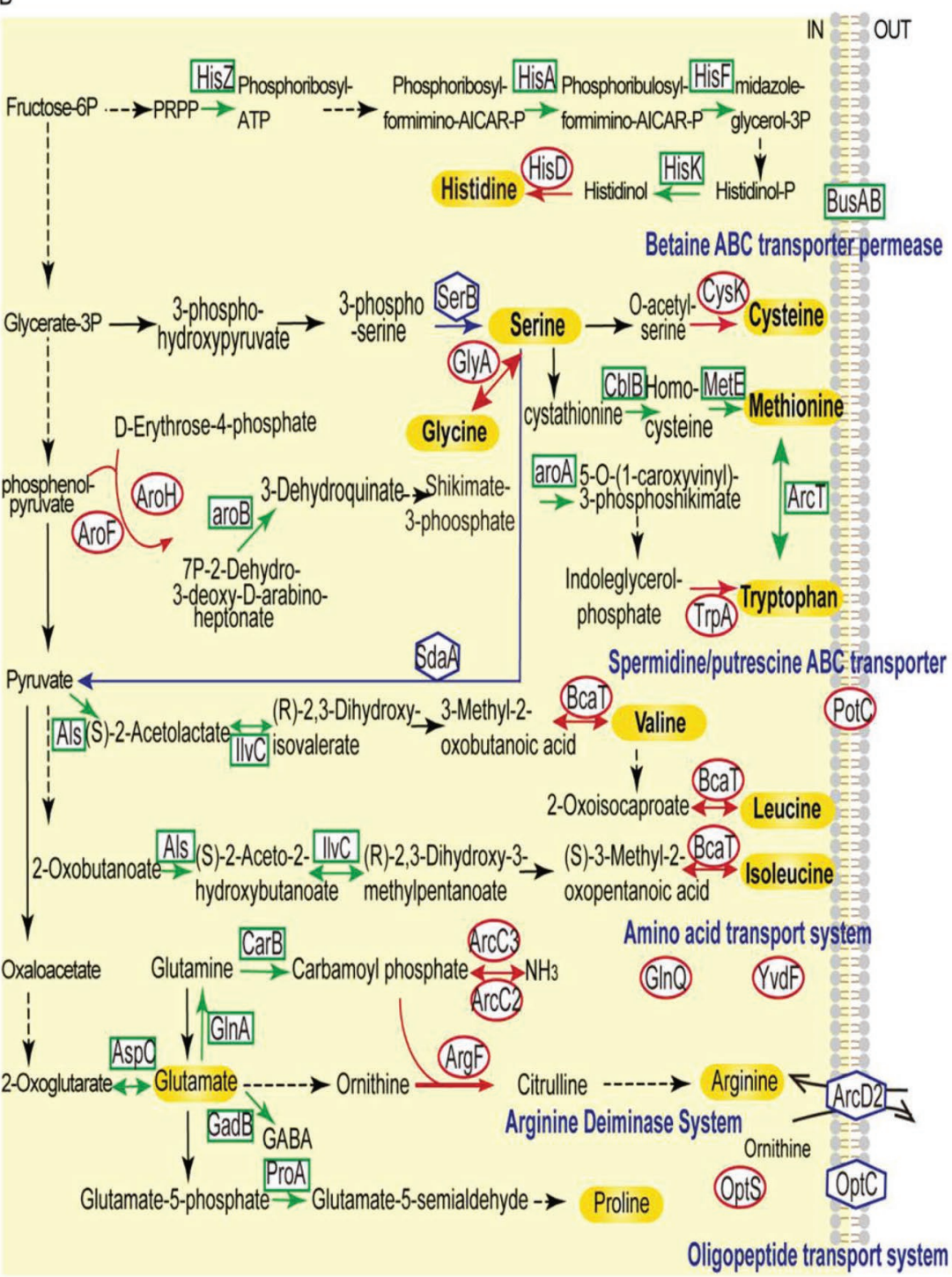

Figure 5. Overview of AA biosynthesis under cross-stress in Lactococcus lactis F44. (A) Heat map of L. lactis F44 AA biosynthesis genes differently expressed (on a $\log _{2}$ scale, $P<0.05$ ) under cross-stress. L0P5 $=\mathrm{pH} 5.0$ without lactic acid, L0P4 $=\mathrm{pH} 4.0$ without lactic acid, L2P7 $=2 \%$ lactic acid with $\mathrm{pH} 7.0, \mathrm{~L} 3 \mathrm{P} 7=3 \%$ lactic acid with $\mathrm{pH} 7.0, \mathrm{~L} 2 \mathrm{P} 5=2 \%$ lactic acid with $\mathrm{pH} 5.0, \mathrm{~L} 2 \mathrm{P} 4=2 \%$ lactic acid with pH 4.0 , $\mathrm{L} 3 \mathrm{P} 5=3 \%$ lactic acid with $\mathrm{pH} 5.0$, and $\mathrm{L} 3 \mathrm{P} 4=3 \%$ lactic acid with $\mathrm{pH}$ 4.0. (B) Simple scheme of AA biosynthesis. The upregulated proteins are in circles. The downregulated proteins are in rectangles. The proteins with inconsistent levels in various comparisons are in hexagons. Color version available online. 
oligopeptide $\mathrm{ABC}$ transporter substrate binding protein OptS was upregulated in $\mathrm{L} 2 \mathrm{P} 4$ versus $\mathrm{L} 0 \mathrm{P} 4, \mathrm{~L} 2 \mathrm{P} 4$ versus L2P7, L3P5 versus L3P7, L3P4 versus L3P7, and L3P4 versus L0P4. On the other hand, OptA (oligopeptide $\mathrm{ABC}$ transporter substrate binding protein) was increased in L3P4 versus L3P7. Oligopeptides are taken up by a specific transport system and then internally hydrolysed by peptidases into AA (Liu et al., 2017). Overall, these results suggested an increased demand for a nitrogen source under cross-stress.

\section{Cross-Stress Affects the Biosynthesis of Ribosomal Proteins and tRNA Synthetases}

Proteomic analysis revealed that cross-stress induced remarkable changes in ribosome synthesis proteins (Supplemental Table S4; https://doi.org/10.3168/ jds.2018-14594). In L2P4 versus L2P7, 11 50S ribosomal proteins, RplC, RplJ, RplN, RplR, RplT, RplX, RpmA, RpmB, RpmC, RpmE, and RpmG3, and 9 30S ribosomal proteins, RpsF, RpsQ, RpsS, RpsE, RpsR, RpsP, RpsT, RpsB, and RpsU, were upregulated. Protein $\mathrm{RpsU}$ was significantly increased in the majority of comparisons, which demonstrated that RpsU played an essential role in L. lactis under cross-stress. Previous experiments showed the rps $U$ gene $(30 \mathrm{~S}$ small subunit ribosomal protein $\mathrm{S} 21$ ) is closely tied to stress resistance and growth at low temperature in L. monocytogenes (Metselaar et al., 2015). In Bacillus subtilis, deletion of rps $U$ resulted in a reduced growth rate and reduced motility (Akanuma et al., 2012). On the other hand, 2 ribosomal proteins, RplM and RpsS, were increased in Lactobacillus bulgaricus CAUH1 under acid stress (Zhai et al., 2014). The genes encoding ribosomal proteins L31 and L25 were also associated with stress resistance in B. subtilis (Zhai et al., 2014; Zhang et al., 2016). Furthermore, these proteins not only constitute the ribosomal subunits related to translation, but also participate in sensing environmental change (VanBogelen and Neidhardt, 1990; Wehmeier et al., 2001; Zhai et al., 2014). These results indicated that increasing the expressions of ribosome synthesis proteins was a global response to lactic acid cross-stress.

Translation initiation factor (IF) IF-3 and IF-1 were upregulated in most comparisons. The 3 canonical IF, IF1, IF2, and IF3, are important in the regulation of the rate and fidelity of translation initiation (MacDougall and Gonzalez, 2015). Conversely, the expressions of most tRNA synthetases (TyrS, LysS2, MetS, LeuS, GlyQ, GlyS, AlaS, CysS, IleS, AspS, HisS, ProS, and ValS) were repressed in the comparisons (L2P4 vs. L2P7, L2P4 vs. L0P4, and L3P4 vs. L0P4). Therefore, we hypothesized that a disorder in protein translation is a major problem for undissociated lactic acid.

\section{Protective Effect of lons Induced by Lactic Acid Cross-Stress}

Iron, which is essential for various cellular functions, can be incorporated into several proteins, such as ribonucleotide reductase enzymes and superoxide dismutases (Lau et al., 2016). In response to environmental changes, bacteria attempt to maintain iron homeostasis. Under lactic acid cross-stress, the expression levels of proteins associated with the metabolism and transport of several ions, such as copper, iron, manganese, and zinc, were enhanced (Supplemental Table S4; https://doi.org/10.3168/jds.2018-14594). Copper homeostasis protein CutC was 1.27-fold and 1.23-fold upregulated at $\mathrm{L} 2 \mathrm{P} 4$ versus $\mathrm{L} 0 \mathrm{P} 4$ and $\mathrm{L} 3 \mathrm{P} 4$ versus L0P4, respectively. Copper is an important cofactor in redox enzymes to ensure cell growth under acid stress, and our results are in agreement with those of a study on L. bulgaricus and L. plantarum 423 (Penaud et al., 2006; Heunis et al., 2014). Moreover, cross-stress facilitated the increase of iron-related proteins. In comparisons L2P4 versus L2P7, L2P4 versus L0P4, L3P5 versus L3P7, L3P5 versus L0P5, and L3P4 versus $\mathrm{L} 3 \mathrm{P} 7, \mathrm{Fe}^{3+}$-siderophore $\mathrm{ABC}$ transporter FeuA was more abundant, and the expression level of FeuA was upregulated at $\mathrm{L} 2 \mathrm{P} 4$ versus $\mathrm{L} 2 \mathrm{P} 7$ (2.07-fold) and L2P4 versus L0P4 (1.91-fold). Non-heme iron-binding ferritin DpsA was increased in L2P4 versus L0P4 (2.42fold) and L3P4 versus L3P7 (3.24-fold). Ferrichrome $\mathrm{ABC}$ transporter substrate binding protein $\mathrm{FhuD}$ was 1.93-fold upregulated at L2P4 versus L2P7. Non-heme iron-binding ferritin DpsA, which is a stress-inducible polypeptide binding DNA, prevents DNA-scission under oxidative stress (Durham and Bullerjahn, 2002). In Helicobacter pylori, the transcriptional level of the non-heme iron-containing ferritin (HP-ferritin), which is essential for iron storage, was enhanced at $\mathrm{pH} 5.0$ compared with $\mathrm{pH}$ 7.0, and the DNA-binding activity was also increased under acidic conditions (Huang et al., 2010). Non-heme iron-containing ferritin can protect $H$. pylori from increasing iron toxicity under acidic conditions, which is presumably caused by the iron-mediated Fenton reaction (Henle et al., 1996). Phosphonate ABC transporter PhnD involved in the phosphonate uptake pathway (Jochimsen et al., 2011) was enhanced in the majority of comparisons, especially in L2P4 versus L2P7 (2.19-fold).

\section{CONCLUSIONS}

In this study, we explored the response mechanisms to the cross-stress of $\mathrm{H}^{+}$and lactate using quantitative proteomic analysis. The results showed that $L$. lactis F44 cells exhibited complex response mechanisms 
under the cross-stress of low $\mathrm{pH}$ and lactate, such as enhancing ribosome synthesis, improving protein folding and DNA repair, generating alkaline substances, increasing the compactness of cell walls, and modulating transcriptional regulation. This study established a model for global response mechanisms to cross-stress of $\mathrm{H}^{+}$and lactate and provided more possibilities for constructing robust industrial strains.

\section{ACKNOWLEDGMENTS}

This study was supported by the National Key R\&D Program of China (2017YFD0201405), the National Natural Science Foundation of China (31570089, 31170076), and the Funds for Creative Research Groups of China (21621004). Jianjun Qiao was supported by The New Century Outstanding Talent Support Program, Education Ministry of China (Beijing).

\section{REFERENCES}

Akanuma, G., H. Nanamiya, Y. Natori, K. Yano, S. Suzuki, S. Omata, M. Ishizuka, Y. Sekine, and F. Kawamura. 2012. Inactivation of ribosomal protein genes in Bacillus subtilis reveals importance of each ribosomal protein for cell proliferation and cell differentiation. J. Bacteriol. 194:6282-6291.

An, H., F. P. Douillard, G. Wang, Z. Zhai, J. Yang, S. Song, J. Cui, F. Ren, Y. Luo, and B. Zhang. 2014. Integrated transcriptomic and proteomic analysis of the bile stress response in a centenarianoriginated probiotic Bifidobacterium longum BBMN68. Mol. Cell. Proteomics 13:2558-2572.

Arena, S., C. D'Ambrosio, G. Renzone, R. Rullo, L. Ledda, F. Vitale, G. Maglione, M. Varcamonti, L. Ferrara, and A. Scaloni. 2006. A study of Streptococcus thermophilus proteome by integrated analytical procedures and differential expression investigations. Proteomics 6:181-192.

Axe, D. D., and J. E. Bailey. 1995. Transport of lactate and acetate through the energized cytoplasmic membrane of Escherichia coli. Biotechnol. Bioeng. 47:8-19.

Biswas, T., J. Small, O. Vandal, T. Odaira, H. Deng, S. Ehrt, and O. V. Tsodikov. 2010. Structural insight into serine protease Rv3671c that protects $M$. tuberculosis from oxidative and acidic stress. Structure 18:1353-1363.

Broadbent, J. R., R. L. Larsen, V. Deibel, and J. L. Steele. 2010. Physiological and transcriptional response of Lactobacillus casei ATCC 334 to acid stress. J. Bacteriol. 192:2445-2458.

Budin-Verneuil, A., V. Pichereau, Y. Auffray, D. S. Ehrlich, and E. Maguin. 2005. Proteomic characterization of the acid tolerance response in Lactococcus lactis MG1363. Proteomics 5:4794-4807.

Castro, R., A. R. Neves, L. L. Fonseca, W. A. Pool, J. Kok, O. P. Kuipers, and H. Santos. 2009. Characterization of the individual glucose uptake systems of Lactococcus lactis: Mannose-PTS, cellobiose-PTS and the novel GlcU permease. Mol. Microbiol. 71:795806.

Cotter, P. D., and C. Hill. 2003. Surviving the acid test: Responses of gram-positive bacteria to low $\mathrm{pH}$. Microbiol. Mol. Biol. Rev. 67:429-453.

De Biase, D., and E. Pennacchietti. 2012. Glutamate decarboxylasedependent acid resistance in orally acquired bacteria: Function, distribution and biomedical implications of the gadBC operon. Mol. Microbiol. 86:770-786.

Desmond, C., G. F. Fitzgerald, C. Stanton, and R. P. Ross. 2004. Improved stress tolerance of GroESL-overproducing Lactococcus lactis and probiotic Lactobacillus paracasei NFBC 338. Int. J. Food Microbiol. 70:5929-5936.
Durham, K. A., and G. S. Bullerjahn. 2002. Immunocytochemical localization of the stress-induced DpsA protein in the cyanobacterium Synechococcus sp. strain PCC 7942. J. Basic Microbiol. 42:367-372.

Eyal, A. M., and R. Canari. 1995. pH dependence of carboxylic and mineral acid extraction by amine-based extractants: Effects of $\mathrm{p} K_{\mathrm{a}}$, amine basicity, and diluent properties. Ind. Eng. Chem. Res. 34:1789-1798.

Fernández, M., and M. Zúñiga. 2006. Amino acid catabolic pathways of lactic acid bacteria. Crit. Rev. Microbiol. 32:155-183.

Frees, D., U. Gerth, and H. Ingmer. 2014. Clp chaperones and proteases are central in stress survival, virulence and antibiotic resistance of Staphylococcus aureus. Int. J. Med. Microbiol. 304:142-149.

Frees, D., F. K. Vogensen, and H. Ingmer. 2003. Identification of proteins induced at low $\mathrm{pH}$ in Lactococcus lactis. Int. J. Food Microbiol. 87:293-300.

Gruening, P., M. W. P. Fulde, and R. Goethe. 2006. Structure, regulation, and putative function of the arginine deiminase system of Streptococcus suis. J. Bacteriol. 188:361-369.

Guerra, N., and L. Pastrana. 2003. Influence of $\mathrm{pH}$ drop on both nisin and pediocin production by Lactococcus lactis and Pediococcus acidilactici. Lett. Appl. Microbiol. 37:51-55.

Hanna, M. N., R. J. Ferguson, Y. H. Li, and D. G. Cvitkovitch. 2001. uvrA is an acid-inducible gene involved in the adaptive response to low pH in Streptococcus mutans. J. Bacteriol. 183:5964-5973.

Henle, E. S., Y. Luo, W. Gassmann, and S. Linn. 1996. Oxidative damage to DNA constituents by iron-mediated fenton reactions. The deoxyguanosine family. J. Biol. Chem. 271:21177-21186.

Heunis, T., S. Deane, S. Smit, and L. M. Dicks. 2014. Proteomic profiling of the acid stress response in Lactobacillus plantarum 423. J. Proteome Res. 13:4028-4039.

Huang, C.-H., I.-L. Lee, I.-J. Yeh, J.-H. Liao, C.-L. Ni, S.-H. Wu, and S.-H. Chiou. 2010. Upregulation of a non-heme iron-containing ferritin with dual ferroxidase and DNA-binding activities in Helicobacter pylori under acid stress. J. Biochem. 147:535-543.

Igarashi, K., and K. Kashiwagi. 2010. Modulation of cellular function by polyamines. Int. J. Biochem. Cell Biol. 42:39-51.

Igarashi, K., and K. Kashiwagi. 2015. Modulation of protein synthesis by polyamines. IUBMB Life 67:160-169.

Jeamton, W., S. Mungpakdee, M. Sirijuntarut, P. Prommeenate, S. Cheevadhanarak, M. Tanticharoen, and A. Hongsthong. 2008. A combined stress response analysis of Spirulina platensis in terms of global differentially expressed proteins, and mRNA levels and stability of fatty acid biosynthesis genes. FEMS Microbiol. Lett. 281:121-131.

Jochimsen, B., S. Lolle, F. R. McSorley, M. Nabi, J. Stougaard, D. L. Zechel, and B. Hove-Jensen. 2011. Five phosphonate operon gene products as components of a multi-subunit complex of the carbon-phosphorus lyase pathway. Proc. Natl. Acad. Sci. USA 108:11393-11398.

Kang, K.-H., J.-S. Lee, M. Yoo, and I. Jin. 2010. The influence of HtrA expression on the growth of Streptococcus mutans during acid stress. Mol. Cells 29:297-304.

Koponen, J., K. Laakso, K. Koskenniemi, M. Kankainen, K. Savijoki, T. A. Nyman, W. M. de Vos, S. Tynkkynen, N. Kalkkinen, and P. Varmanen. 2012. Effect of acid stress on protein expression and phosphorylation in Lactobacillus rhamnosus GG. J. Proteomics 75:1357-1374.

Lau, C. K., K. D. Krewulak, and H. J. Vogel. 2016. Bacterial ferrous iron transport: The Feo system. FEMS Microbiol. Rev. 40:273-298.

Lee, K., H. G. Lee, K. Pi, and Y. J. Choi. 2008. The effect of low pH on protein expression by the probiotic bacterium Lactobacillus reuteri. Proteomics 8:1624-1630.

Len, A. C., D. W. Harty, and N. A. Jacques. 2004. Proteome analysis of Streptococcus mutans metabolic phenotype during acid tolerance. Microbiology 150:1353-1366.

Liang, W.-D., Y.-T. Bi, H.-Y. Wang, S. Dong, K.-S. Li, and J.-S. Li. 2013. Gene expression profiling of Clostridium botulinum under heat shock stress. BioMed Res. Int. 760904. https://doi.org/10 $.1155 / 2013 / 760904$. 
Liu, J., J. Zhou, L. Wang, Z. Ma, G. Zhao, Z. Ge, H. Zhu, and J. Qiao. 2017. Improving nitrogen source utilization from defatted soybean meal for nisin production by enhancing proteolytic function of Lactococcus lactis F44. Sci. Rep. 7:6189. https://doi.org/10 .1038/s41598-017-06537-w.

Lucas, P. M., V. S. Blancato, C. Olivier, M. Christian, J. S. Lolkema and L. F. Aline. 2007. Agmatine deiminase pathway genes in Lactobacillus brevis are linked to the tyrosine decarboxylation operon in a putative acid resistance locus. Microbiology 153:2221-2230.

MacDougall, D. D., and R. L. Gonzalez. 2015. Translation initiation factor 3 regulates switching between different modes of ribosomal subunit joining. J. Mol. Biol. 427:1801-1818.

Marquis, R. E., G. R. Bender, D. R. Murray, and A. Wong. 1987. Arginine deiminase system and bacterial adaptation to acid environments. Appl. Environ. Microbiol. 53:198-200.

Metselaar, K. I., H. M. den Besten, J. Boekhorst, S. A. van Hijum, M. H. Zwietering, and T. Abee. 2015. Diversity of acid stress resistant variants of Listeria monocytogenes and the potential role of ribosomal protein S21 encoded by rpsU. Front. Microbiol. 6:422. https://doi.org/10.3389/fmicb.2015.00422.

Montanari, C., S. L. S. Kamdem, D. I. Serrazanetti, F. X. Etoa, and M. E. Guerzoni. 2010. Synthesis of cyclopropane fatty acids in Lactobacillus helveticus and Lactobacillus sanfranciscensis and their cellular fatty acids changes following short term acid and cold stresses. Food Microbiol. 27:493-502.

Morgan-Kiss, R. M., and J. E. Cronan. 2004. The Escherichia coli fadK (ydiD) gene encodes an anerobically regulated short chain acyl-CoA synthetase. J. Biol. Chem. 279:37324-37333.

Penaud, S., A. Fernandez, S. Boudebbouze, S. Ehrlich, E. Maguin, and M. Van De Guchte. 2006. Induction of heavy-metal-transporting CPX-type ATPases during acid adaptation in Lactobacillus bulgaricus. Appl. Environ. Microbiol. 72:7445-7454.

Pieterse, B., R. J. Leer, F. H. Schuren, and M. J. van der Werf. 2005. Unravelling the multiple effects of lactic acid stress on Lactobacillus plantarum by transcription profiling. Microbiology 151:3881-3894.

Pool, W. A., A. R. Neves, J. Kok, H. Santos, and O. P. Kuipers. 2006. Natural sweetening of food products by engineering Lactococcus lactis for glucose production. Metab. Eng. 8:456-464.

Qiao, J., J. Wang, L. Chen, X. Tian, S. Huang, X. Ren, and W. Zhang. 2012. Quantitative iTRAQ LC-MS/MS proteomics reveals metabolic responses to biofuel ethanol in cyanobacterial Synechocystis sp. PCC 6803. J. Proteome Res. 11:5286-5300.

Redko, Y., P. Courtin, C. Mézange, C. Huard, and M.-P. ChapotChartier. 2007. Lactococcus lactis gene yjgB encodes a $\gamma$-dglutaminyl-l-lysyl-endopeptidase which hydrolyzes peptidoglycan. Appl. Environ. Microbiol. 73:5825-5831.

Rosengren, Å., M. Lindblad, and R. Lindqvist. 2013. The effect of undissociated lactic acid on Staphylococcus aureus growth and enterotoxin A production. Int. J. Food Microbiol. 162:159-166.

Russell, J. B. 1992. Another explanation for the toxicity of fermentation acids at low pH: Anion accumulation versus uncoupling. J. Appl. Bacteriol. 73:363-370.

Russell, J. B., and F. Diez-Gonzalez. 1998. The effects of fermentation acids on bacterial growth. Adv. Microb. Physiol. 39:205-234.

Saibil, H. 2013. Chaperone machines for protein folding, unfolding and disaggregation. Nat. Rev. Mol. Cell Biol. 14:630.

Sánchez, B., M.-C. Champomier-Vergès, M. del Carmen Collado, P. Anglade, F. Baraige, Y. Sanz, G. Clara, A. Margolles, and M. Zagorec. 2007. Low-pH adaptation and the acid tolerance response of Bifidobacterium longum biotype longum. Appl. Environ. Microbiol. 73:6450-6459.

Shelef, L. A. 1994. Antimicrobial effects of lactates: A review. J. Food Prot. 57:445-450.

Shimizu, H. T., E. Tanaka, and S. Shioya. 1999. Nisin production by a mixed-culture system consisting of Lactococcus lactis and Kluyveromyces marxianus. Appl. Environ. Microbiol. 65:3134-3141.

Singh, K., D. B. Senadheera, C. M. Lévesque, and D. G. Cvitkovitch. 2015. The copYAZ operon functions in copper efflux, biofilm formation, genetic transformation, and stress tolerance in Streptococcus mutans. J. Bacteriol. 197:2545-2557.
Song, A. A.-L., L. L. In, S. H. E. Lim, and R. A. Rahim. 2017. A review on Lactococcus lactis: From food to factory. Microb. Cell Fact. 16:55. https://doi.org/10.1186/s12934-017-0669-x.

Steen, A., G. Buist, G. J. Horsburgh, G. Venema, O. P. Kuipers, S. J. Foster, and J. Kok. 2005. AcmA of Lactococcus lactis is an Nacetylglucosaminidase with an optimal number of LysM domains for proper functioning. FEBS J. 272:2854-2868.

Sun, T., L. Chen, and W. Zhang. 2017. Quantitative proteomics reveals potential crosstalk between a small RNA CoaR and a twocomponent regulator Slr1037 in Synechocystis sp. PCC6803. J. Proteome Res. 16:2954-2963.

To, T. M. H., C. Grandvalet, and R. Tourdot-Maréchal. 2011. Cyclopropanation of membrane unsaturated fatty acids is not essential to the acid stress response of Lactococcus lactis ssp. cremoris. Appl. Environ. Microbiol. 77:3327-3334.

VanBogelen, R. A.. and F. C. Neidhardt. 1990. Ribosomes as sensors of heat and cold shock in Escherichia coli. Proc. Natl. Acad. Sci USA 87:5589-5593.

Visweswaran, G. R. R., A. Steen, K. Leenhouts, M. Szeliga, B. Ruban A. Hesseling-Meinders, B. W. Dijkstra, O. P. Kuipers, J. Kok, and G. Buist. 2013. AcmD, a homolog of the major autolysin AcmA of Lactococcus lactis, binds to the cell wall and contributes to cell separation and autolysis. PLoS One 8:e72167.

Vrancken, G., T. Rimaux, D. Wouters, F. Leroy, and L. D. Vuyst. 2009. The arginine deiminase pathway of Lactobacillus fermentum IMDO 130101 responds to growth under stress conditions of both temperature and salt. Food Microbiol. 26:720-727.

Wall, T., K. Båth, R. A. Britton, H. Jonsson, J. Versalovic, and S. Roos. 2007. The early response to acid shock in Lactobacillus reuteri involves the $\mathrm{ClpL}$ chaperone and a putative cell wall-altering esterase. Appl. Environ. Microbiol. 73:3924-3935.

Wehmeier, L., O. Brockmann-Gretza, A. Pisabarro, A. Tauch, A. Pühler, J. F. Martin, and J. Kalinowski. 2001. A Corynebacterium glutamicum mutant with a defined deletion within the rplK gene is impaired in (p) ppGpp accumulation upon amino acid starvation. Microbiology 147:691-700.

Wu, C., J. Zhang, W. Chen, M. Wang, G. Du, and J. Chen. 2012. A combined physiological and proteomic approach to reveal lacticacid-induced alterations in Lactobacillus casei Zhang and its mutant with enhanced lactic acid tolerance. Appl. Microbiol. Biotechnol. 93:707-722.

Xie, Y., L.-s. Chou, A. Cutler, and B. Weimer. 2004. DNA macroarray profiling of Lactococcus lactis ssp. lactis IL1403 gene expression during environmental stresses. Appl. Environ. Microbiol. 70:6738 6747.

Zhai, Z., H. An, G. Wang, Y. Luo, and Y. Hao. 2015. Functional role of pyruvate kinase from Lactobacillus bulgaricus in acid tolerance and identification of its transcription factor by bacterial one-hybrid. Sci. Rep. 5:17024.

Zhai, Z., F. P. Douillard, H. An, G. Wang, X. Guo, Y. Luo, and Y. Hao. 2014. Proteomic characterization of the acid tolerance response in Lactobacillus delbrueckii ssp. bulgaricus CAUH1 and functional identification of a novel acid stress-related transcriptional regulator Ldb0677. Environ. Microbiol. 16:1524-1537.

Zhang, J., Q. Caiyin, W. Feng, X. Zhao, B. Qiao, G. Zhao, and J. Qiao. 2016. Enhance nisin yield via improving acid-tolerant capability of Lactococcus lactis F44. Sci. Rep. 6:27973.

Zhang, J., R.-Y. Fu, J. Hugenholtz, Y. Li, and J. Chen. 2007. Glutathione protects Lactococcus lactis against acid stress. Appl. Environ. Microbiol. 73:5268-5275.

Zhang, L., W. Liu, T. Hu, L. Du, C. Luo, K. Chen, X. Shen, and H. Jiang. 2008. Structural basis for catalytic and inhibitory mechanisms of $\beta$-hydroxyacyl-acyl carrier protein dehydratase (FabZ). J. Biol. Chem. 283:5370-5379

Zhang, X., Y. Zhang, J. Liu, and H. Liu. 2013. PotD protein stimulates biofilm formation by Escherichia coli. Biotechnol. Lett. 35:10991106 . 